\title{
Left ventricular myocardial deformation: a study on diastolic function in the Chinese male population and its relationship with fat distribution
}

\author{
Lan Zhu', Shengjia Gu${ }^{1}$, Qingrou Wang ${ }^{1}$, Xiaoyue Zhou ${ }^{2}$, Simin Wang ${ }^{1}$, Caixia Fu ${ }^{3}$, Wenjie Yang ${ }^{1}$, Jens \\ Wetzl $^{4}$, Fuhua Yan ${ }^{1}$ \\ ${ }^{1}$ Department of Radiology, Ruijin Hospital, Shanghai Jiao Tong University School of Medicine, Shanghai 200025, China; ${ }^{2}$ Collaboration, Siemens Healthcare \\ Ltd., Shanghai 201318, China; ${ }^{3}$ Siemens Shenzhen Magnetic Resonance Ltd, Shenzhen 518057, China; ${ }^{4}$ Siemens Healthcare, Erlangen, Germany
}

Correspondence to: Fuhua Yan. Department of Radiology, Ruijin Hospital, Shanghai Jiao Tong University School of Medicine, Shanghai 200025, China. Email: yfh11655@rjh.com.cn.

Background: Obesity has become an epidemic in China with its increased prevalence, especially in the male population. Disparities in fat distribution rather than increasing body mass index (BMI) confer the risk of different diseases, including cardiac abnormalities. Therefore, early detection of cardiac abnormalities is important for treatment to reverse the progression to heart failure. Nowadays, strain analysis based on cardiac magnetic resonance $(\mathrm{CMR})$ imaging has been established to assess myocardial function in diverse cardiac diseases. We aimed to assess the relationship between fat distribution and subclinical diastolic dysfunction in obese Chinese men assessed by deformation registration algorithm (DRA)-based myocardial strain rate (SR) analysis.

Methods: A total of 115 male participants with different BMI underwent CMR scanning using a $1.5 \mathrm{~T}$ MAGNETOM Aera (Siemens Healthcare, Erlangen, Germany) and computed tomography (CT) scan. All the participants were enrolled from September 2017 to April 2018. They were classified into 3 groups according to their BMIs with 23 and $27.5 \mathrm{~kg} / \mathrm{m}^{2}$ being the cutoff values. A Trufi-Strain prototype software (version 2.0, Siemens Healthcare, Erlangen, Germany) was used to quantify SR in both early and late diastole from CMR cine images. Ratios of early and late SRs were calculated. Areas of epicardial and pericardial adipose tissue (EAT and PAT) were measured on a single 4-chamber-view slice of cine images. Volumes of visceral and subcutaneous adipose tissue (VAT and SAT) were acquired semi-automatically from CT images using the dedicated software Cardiac Risk2.0 (Siemens Healthcare). Waist and hip circumferences were manually measured (WC and HC). Analysis of variance or nonparametric tests, along with correlation and stepwise multivariate regression analysis models, was applied for statistical analysis.

Results: Peak late diastolic SRs were higher in obese men compared with their lean counterparts $[-36.25 \pm 10.46$ vs. $-29.46 \pm 8.17,66.97 \pm 18.58$ vs. $45.62(42.44,55.96)$, and $56.81 \pm 15.07 v s .41 .40 \pm 6.41$ for radial, circumferential, and longitudinal SRs, respectively; $\mathrm{P}<0.05]$. All SR ratios in the obese subgroups were lower than those of lean men $(3.12 \pm 1.14$ vs. $4.63 \pm 1.24,2.12 \pm 0.58$ vs. $2.96 \pm 0.62$ and $1.63 \pm 0.50$ vs. $2.20 \pm 0.63$ for radial, circumferential, and longitudinal directions, respectively; $\mathrm{P}<0.05)$. EAT was a significant predictor of diastolic function assessed by radial and circumferential SR ratios ( $\beta=-0.439$ and -0.337 respectively; all $\mathrm{P}<0.001)$, while VAT was a significant predictor of circumferential and longitudinal SR ratios $(\beta=-0.216$ and -0.355 , respectively, $\mathrm{P}<0.05)$.

Conclusions: Decreased LV diastolic function assessed by DRA-based SR analysis in obesity is associated with fat distribution. Furthermore, EAT and VAT might be better predictors of a decrease of diastolic function in obese Chinese men than BMI.

Keywords: Diastolic function; obesity; cardiac magnetic resonance (CMR); strain rate analysis; Chinese men

Submitted Aug 30, 2019. Accepted for publication Jan 14, 2020.

doi: 10.21037 /qims.2020.01.16

View this article at: http://dx.doi.org/10.21037/qims.2020.01.16 


\section{Introduction}

Over the last 2 decades, obesity has become a severe epidemic in China, especially in the male population (1). Being overweight and obese confer an elevated risk of adverse consequences, including hypertension, diabetes, and cardiovascular disease (2). Long-term obesity can induce left ventricular (LV) structural and functional abnormalities (3-6). Hence, early detection of cardiac abnormalities is important in reversing the progression to heart failure.

Body mass index (BMI), the most used index of obesity, is associated with documented obesity-related comorbidities (2). However, it is often not dependable for estimating an individual's fat distribution due to the heterogeneity of obesity (7). Disparities in fat distribution confer the risk of different diseases. For instance, an individual with "apple" obesity has a higher risk of metabolic syndrome than one with "pear" obesity with the same BMI (8). Thus, it is important to identify individual fat distribution for predicting the risk of comorbidities. Unfortunately, although patterns of fat distribution differ across race (7), few articles have focused on the Asian or Chinese population (9-12).

Strain is defined as the change during a cardiac cycle in fiber length divided by the original length using the following equation: $\varepsilon=(\mathrm{L}-\mathrm{L} 0) / \mathrm{L} 0$; where $\varepsilon=$ myocardial strain, $\mathrm{L}=$ length at end-systole, $\mathrm{L} 0=$ initial length measured at end-diastole. Myocardial strain reflects myocardial deformation and is associated with both myocyte metabolism and contractility. Strain rate (SR) describes the rate of shortening or lengthening of the myocardium (13). Earlier studies have revealed incipient diastolic dysfunction in obesity through strain/SR analysis by echocardiography $(6,14,15)$. Nowadays, strain/SR analysis based on steadystate free-precession (SSFP) cine cardiac magnetic resonance (CMR) imaging has been employed to assess myocardial function in heart diseases (16-18). As a pixelbased strain/SR analysis tool, the deformation registration algorithm (DRA) of cine images has demonstrated better reproducibility and accuracy than both widely used CMR feature-tracking and echocardiography $(19,20)$. DRAbased strain analysis has also been proposed for describing myocardial motion and function in cardiac diseases $(20,21)$.

This study aimed to assess the relationship between fat distribution and subclinical diastolic dysfunction in obese Chinese men assessed by DRA-based myocardial SR analysis.

\section{Methods}

This prospective study was approved by the institutional review board, and written informed consent was obtained from each participant.

\section{Study population}

Between September 2017 and April 2018, 154 male volunteers aged from 20 to 79 years old from Shanghai initially agreed to participate. Seven of them were excluded based on the following exclusion criteria: (I) hypertension and/or diabetes mellitus with/without medication (n=7); (II) cardiovascular disease, including ischemic and non-ischemic cardiomyopathy, heart valve diseases, congenital heart disease, and/or any cardiovascular procedures $(\mathrm{n}=0)$; (III) major systemic disease likely to affecting the myocardium such as systemic lupus erythematosus $(\mathrm{n}=0)$; (IV) any contraindication to CMR $(\mathrm{n}=0)$. Then, the remaining 147 volunteers underwent routine blood chemistry analysis and sitting blood pressure measurements. Another 9 subjects were further excluded because of newly detected hypertension and/or dysglycemia defined as below. Some participants who had refused computed tomography (CT scanning $(n=21)$ owing to radiation exposure were then excluded. Most of the remaining patients $(\mathrm{n}=117)$ underwent both CMR and CT imaging the day after the above tests. Another 2 sets of CMR images were not suitable for further analysis because of wrap-around artifacts. Finally, 115 volunteers (median age, 33 years; age range, 23-59 years) were involved and grouped based on BMI as obese (BMI $\geq 27.5 \mathrm{~kg} / \mathrm{m}^{2} ; \mathrm{n}=32$ ), overweight (BMI, 23 to $\left.27.5 \mathrm{~kg} / \mathrm{m}^{2} ; \mathrm{n}=60\right)$, and lean $\left(\mathrm{BMI}<23 \mathrm{~kg} / \mathrm{m}^{2}, \mathrm{n}=23\right.$ ) subjects, according to criteria suggested by the China Physical Fitness Surveillance Center (1).

\section{Anthropometric parameters and blood pressure measurement}

Weight and height were measured in light clothing without shoes using a mechanical weighing scale with a height rod (Suhong, Jiangsu, China). Waist circumference (WC) was measured at the mid-point between the iliac crest and the lower rib margin, while hip circumference (HC) was measured as the maximum circumference around the buttocks posteriorly and the pubic symphysis anteriorly. Waist-to-hip ratio (WHR) and BMI $\left(\mathrm{kg} / \mathrm{m}^{2}\right)$ were also 
calculated.

Blood pressure was measured using an appropriately sized cuff after at least a 30-minute rest, and hypertension was defined as systolic blood pressure $\geq 140 \mathrm{mmHg}$ and/or diastolic blood pressure $\geq 90 \mathrm{mmHg}$.

\section{Biochemical tests}

Venous blood samples following 12-hour fasting were collected for biochemical analysis on a Beckman Coulter AU 5800 (Beckman Coulter, CA, USA).

Dyslipidemia was defined when achieving one of following: (I) total cholesterol $>5.7 \mathrm{mmol} / \mathrm{L}$, (II) triglycerides $>1.7 \mathrm{mmol} / \mathrm{L}$, (III) low-density lipoprotein cholesterol $>4.3 \mathrm{mmol} / \mathrm{L}$, (IV) high-density lipoprotein cholesterol $<0.8 \mathrm{mmol} / \mathrm{L}$.

Impaired fasting glycemia or dysglycemia was defined as fasting glucose $\geq 6.1 \mathrm{mmol} / \mathrm{L}$.

\section{Volumetric measurements of visceral and subcutaneous} adipose tissues (VAT and SAT)

Subjects underwent 64-slice multidetector abdominopelvic (from the top of the diaphragm to the pubic symphysis) non-enhanced CT scanning (SOMATOM Definition Flash; Siemens Healthcare, Erlangen, Germany) in the supine position with the following configuration: voltage, $120 \mathrm{kV}$; pitch, 0.6; gantry rotation, $0.5 \mathrm{~s}$; slice thickness, $5 \mathrm{~mm}$; variable mAs using automated dose modulation (CARE Dose 4D, Siemens Healthcare). All images were reconstructed in $1.0 \mathrm{~mm}$ thick slice with a medium-smooth kernel (B31f) and body-soft-tissue algorithm.

The reconstructed images of all slices were loaded into the prototype software (Cardiac Risk Assessment 2.0, Siemens Healthcare). The abdominal muscular wall separating the 2 compartments was manually delineated to separate VAT from SAT, and subsequently automatically traced with thresholds from -150 to -50 Hounsfield unit of fat tissue. SAT and VAT amounts were calculated in $\mathrm{cm}^{3}$ (22).

\section{Measurement of epicardial and pericardial adipose tissues (EAT and PAT) from CMR datasets}

Retrospective electrocardiographic gating CMR was performed using a $1.5 \mathrm{~T}$ imager (MAGNETOM Aera, Siemens Healthcare, Erlangen, Germany) with a sixchannel phased-array body coil along with a spine coil during breath holding. Cine images consisted of a shortaxis stack covering the whole $\mathrm{LV}$, and long-axis images (2-, 3-, and 4-chamber views) were acquired according to the following standardized protocol: repetition time/ echo time (ms), 46.24/1.22; flip angle, 54 ; field of view, 320-440 $\mathrm{mm}^{2}$; matrix, 192 $\times 192$; slice thickness, $8 \mathrm{~mm}$ with a $2-\mathrm{mm}$ gap; mean temporal resolution of $40 \mathrm{~ms}$ with 25 phases per cardiac cycle.

Epicardial adipose tissue (EAT) was defined as the highintensity layer between the myocardium and the visceral sheet of the pericardium. Pericardial adipose tissues (PAT) was defined as the continuum of thoracic adipose tissue outside the parietal pericardium. As in previous studies, EAT and PAT areas were measured in a single 4-chamberview slice and showed a good correlation with fat volumes measured on short-axis images (23-25). The measurement was performed on an end-diastolic single 4-chamberview cine image with an open-source software named $3 \mathrm{D}$ Slicer (26). All phases of cine images were inspected to identify the pericardium, and then EAT and PAT were drawn in different colors. The areas of both EAT and PAT were acquired through multiplying the number of pixels and pixel size by the $3 \mathrm{D}$ slicer.

\section{SR analysis and global morphological and functional parameters based on CMR datasets}

Since SR was less affected by passive myocardial motions than strain and had a uniform distribution throughout the whole LV (27), this study was oriented towards SR instead of strain. The dedicated DRA-based software (TrufiStrain; Siemens Healthcare, Princeton, NJ, USA) was used to automatically generate epi- and endocardial contours for all short-axis images as previously described $(20,28)$. Circumferential and radial strain/SR were assessed with all slices of short-axis images using automatic contours (28). To calculate longitudinal SR, contours of all long-axis images were manually defined in a single end-diastolic phase, and automatically propagated through all phases. SR analysis, along with global morphological and functional parameters, was then assessed. To assess LV diastolic function, peak SRs were measured from the strain curve including peak early diastolic SRs of radial, longitudinal, and circumferential directions $\left(\mathrm{RSR}_{\mathrm{E}}, \mathrm{LSR}_{\mathrm{E}}\right.$, and $\mathrm{CSR}_{\mathrm{E}}$, respectively) and those during late diastole $\left(\mathrm{RSR}_{\mathrm{L}}\right.$, $\mathrm{LSR}_{\mathrm{L}}$, and $\mathrm{CSR}_{\mathrm{L}}$ respectively). Additionally, to imitate. the E/A ratio in echocardiography and to reduce the impact of preload on SR values previously reported (27), 
ratios of early and late diastolic SRs were calculated; i.e., REL, CEL, and LEL for radial, circumferential and longitudinal, respectively.

Global morphological and functional parameters including end-diastolic volume (EDV), end-diastolic mass (EDM), stroke volume (SV), cardiac output (CO), and left ventricular ejection fraction (LVEF) were calculated based on cine short-axis images by TrufiStrain as described in a previous study (29).

\section{Reproducibility of measurements}

Since contours were generated automatically on shortaxis images, it was not necessary to assess the interobserver variations of circumferential and radial SRs. Interobserver variations for longitudinal SRs, EAT, PAT, VAT, and SAT were assessed in 30 randomly selected volunteers by the intra-class correlation coefficient (ICC) between independent radiologists. Two radiologists (Simin Wang and Qingrou Wang) conducted the measurements of SAT and VAT separately, while EAT, PAT, and longitudinal SRs were measured by Shengiia Gu and Lan Zhu. Then, 2 experienced radiologists performed the measurements for all participants (Lan Zhu for EAT, PAT and longitudinal SRs; Qingrou Wang or VAT and SAT). Observers (Simin Wang and Qingrou Wang) had 6 and 8 years of experience in interpreting CT images, while Shengjia Gu and Lan Zhu had 10 and 9 years of experience in cardiovascular images, respectively.

\section{Statistical analysis}

Continuous variables were represented as mean \pm standard deviation (SD) for normally distributed variables or median $\left(25^{\text {th }}-75^{\text {th }}\right.$ quartiles $)$ for non-normally distributed variables, according to the Kolmogorov-Smirnov test. Categorical variables were presented as numbers (proportions, \%).

Group differences were compared by one-way analysis of variance with the least significant difference or nonparametric test on $\mathrm{k}$ independent samples, with a median based on the Levene's test.

Pearson's correlation was used to evaluate the associations of fat distribution parameters (weight, BMI, SAT, VAT, EAT, PAT, WC, HC, WHR) and morphologically diastolic parameters, including EDV, EDM, EDM/V, EDV/body surface area (BSA), EDM/BSA, with SR ratio; Spearman's correlation was performed between dyslipidemia and the SR ratio.

Stepwise multivariate linear regression models were used to estimate contributions of morphological features and fat distribution parameters to diastolic function. Diastolic function varies linearly with age in normal individuals, so all regression models forced entry of age, grouped at 5 -year intervals (age group) at the first stage. Dyslipidemia was included as a dichotomized variable, while BMI was considered a continuous variable. Other selection variables of initial fat distribution, including EAT, PAT, SAT, VAT, weight, BMI, the status of dyslipidemia, and related morphological parameters according to correlation analysis, were entered stepwise at the second stage. The final regression models included only predictors that reached statistical significance. An ICC $>0.75$ was considered to indicate a good agreement (30).

Significance was assumed at $\mathrm{P}<0.05$. All statistical analyses were performed with SPSS (SPSS 22.0, Chicago, IL, USA) and MedCalc (Medcalc17.9, Medcalc, Mariakerke, Belgium).

\section{Results}

The ICCs for measurements by the two radiologists were 0.998 [95\% confidence interval (CI), 0.996-0.999] for VAT, 0.998 (95\% CI, 0.995-0.999) for SAT, 0.927 (95\% CI, 0.849-0.965) for EAT, and 0.980 (95\% CI, 0.957-0.990) for PAT. DRA-based longitudinal SR exhibited excellent agreement with ICCs of 0.966 (95\% CI, 0.924-0.985) and 0.974 (95\% CI, 0.940-0.988) for $\mathrm{LSR}_{\mathrm{E}}$ and $\mathrm{LSR}_{\mathrm{L}}$, respectively.

\section{Clinical characteristics and fat distributions among groups}

Demographic data and fat distribution indices are summarized in Table 1. A total of 115 volunteers were classified into 3 groups according to criteria reported by the China Physical Fitness Surveillance Center (1) as described above.

Age and height were similar among groups. Due to grouping criteria, body fat distribution significantly increased with BMI (Table 1).

\section{Morphological and functional parameters of left ventricle among groups}

The results of measurements are shown in Tables 2 and 3. For morphological characteristics, obese men exhibited significant remodeling with greater EDV and EDM compared with both overweight and lean individuals. However, no significant differences were found after 
Table 1 Differences of fat distributions among groups

\begin{tabular}{|c|c|c|c|c|c|}
\hline Variables & Group 1 (n=32) & Group $2(n=60)$ & Group $3(n=23)$ & Test statistic & $P$ value \\
\hline Age (years) & $30.5(28.0,35.8)$ & $36(30.3,49.3)$ & $30[30,36]$ & 4.679 & 0.096 \\
\hline Heart rate (beat/min) & $64.10 \pm 5.74$ & $67.20 \pm 11.36$ & $68.91 \pm 9.07$ & 1.834 & 0.165 \\
\hline Height (cm) & $173.68 \pm 5.63$ & $173.73 \pm 5.58$ & $176.40 \pm 5.97$ & 2.071 & 0.131 \\
\hline Weight (kg) & $<0.001^{*}$ & $<0.001^{\star \star}$ & $<0.001^{\star \star \star}$ & & \\
\hline \multirow[t]{2}{*}{ VAT $\left(\mathrm{cm}^{3}\right)$} & $1,671.74 \pm 823.40$ & $3,405.85 \pm 1,244.83$ & $5,066.43 \pm 1,006.98$ & 65.266 & $<0.001$ \\
\hline & $<0.001^{*}$ & $<0.001^{\star *}$ & $<0.001^{\star \star *}$ & & \\
\hline $\mathrm{SAT}\left(\mathrm{cm}^{3}\right)$ & $2,929.34 \pm 1,424.35$ & $4,662.67(3,867.41,5,503.72)$ & $10,202.67 \pm 3,952.17$ & 37.235 & $<0.001$ \\
\hline EAT $\left(\mathrm{mm}^{2}\right)$ & $0.001^{*}$ & $0.012^{\star \star}$ & $<0.001^{\star \star \star}$ & & \\
\hline \multirow[t]{2}{*}{ PAT $\left(\mathrm{mm}^{2}\right)$} & $565.84 \pm 282.56$ & $1,095.51 \pm 472.91$ & $1,620.54 \pm 690.74$ & 32.340 & $<0.001$ \\
\hline & $<0.001^{*}$ & $<0.001^{\star \star}$ & $0.003^{\star \star \star}$ & & \\
\hline \multirow[t]{2}{*}{ WC (cm) } & $79.16 \pm 5.67$ & $87.00(85.00,92.00)$ & $104.89 \pm 8.37$ & 74.173 & $<0.001$ \\
\hline & $<0.001^{*}$ & $<0.001^{\star \star}$ & $<0.001^{\star \star \star}$ & & \\
\hline \multirow[t]{2}{*}{$\mathrm{HC}(\mathrm{cm})$} & $95.14 \pm 4.68$ & $99.92 \pm 4.18$ & $112.00 \pm 7.79$ & 72.748 & $<0.001$ \\
\hline & $0.001^{*}$ & $<0.001^{\star \star}$ & $<0.001^{\star \star \star}$ & & \\
\hline WHR & $0.83 \pm 0.05$ & $0.88 \pm 0.04$ & $0.94 \pm 0.04$ & 44.330 & $<0.001$ \\
\hline
\end{tabular}

*, P value for differences between Group 1 and Group 2; **, P value for differences between Group 2 and Group 3; **, P value for differences between Group 1 and Group 3. BMI, body mass index; EAT, epicardial fat; HC, hip circumference; PAT, pericardial adipose tissue; SAT, subcutaneous adipose tissue; VAT, visceral adipose tissue; WC, waist circumference; WHR, waist-to-hip ratio.

normalization to BSA $(\mathrm{P}=0.827$ and $\mathrm{P}=0.229$ for $\mathrm{EDV} / \mathrm{BSA}$ and EDM/BSA, respectively). For clinical function, the elevated hemodynamic state was found in obese individuals with higher SV and CO with similar LVEF, and differences did not persist after adjustment to BSA ( $\mathrm{P}=0.400$ for SV/ BSA and $\mathrm{P}=0.708$ for CO/BSA) (Table 2).

Additionally, obese men showed decreased diastolic function as assessed by SR analysis. During the early diastole, $\mathrm{RSR}_{\mathrm{E}}$ in overweight and obese subjects were lower than those of lean counterparts, although similar $\mathrm{CSR}_{\mathrm{E}}$ and $\mathrm{LSR}_{\mathrm{E}}$ were obtained. Peak late diastolic SRs and all SR ratios were significantly different among groups. Lean men had lower peak late diastolic SRs and higher SR ratios compared with the remaining groups (Table 3 and Figure 1).

\section{Associations of SR ratios and fat distribution with morphological characteristics}

Related data are shown in Table S1. Diastolic function assessed by SR ratio decreased with increasing age $(r=-0.360$ for REL; $r=-0.526$ for CEL; $r=-0.502$ for $L E L$, all $\mathrm{P}<0.001$ ). For associations with fat distribution, SR ratio was inversely correlated with weight, BMI, and intrathoracic fat (EAT and PAT) (REL: $r=-0.239$ for weight, $r=-0.249$ for BMI; $r=-0.482$ for EAT, $r=-0.374$ for PAT; CEL: $r=-0.325$ for weight, $\mathrm{r}=-0.338$ for BMI; $r=-0.478$ for EAT, $r=-0.436$ for PAT; LEL: $r=-0.275$ for weight, $r=-0.306$ for BMI; $r=-0.319$ for EAT, $r=-0.390$ for PAT, all $\mathrm{P}<0.05$ ). For abdominal fat, SR ratio was correlated with VAT and WC (REL: $r=-0.412$ for 
Table 2 Differences of general cardiac morphological and functional characteristics among groups

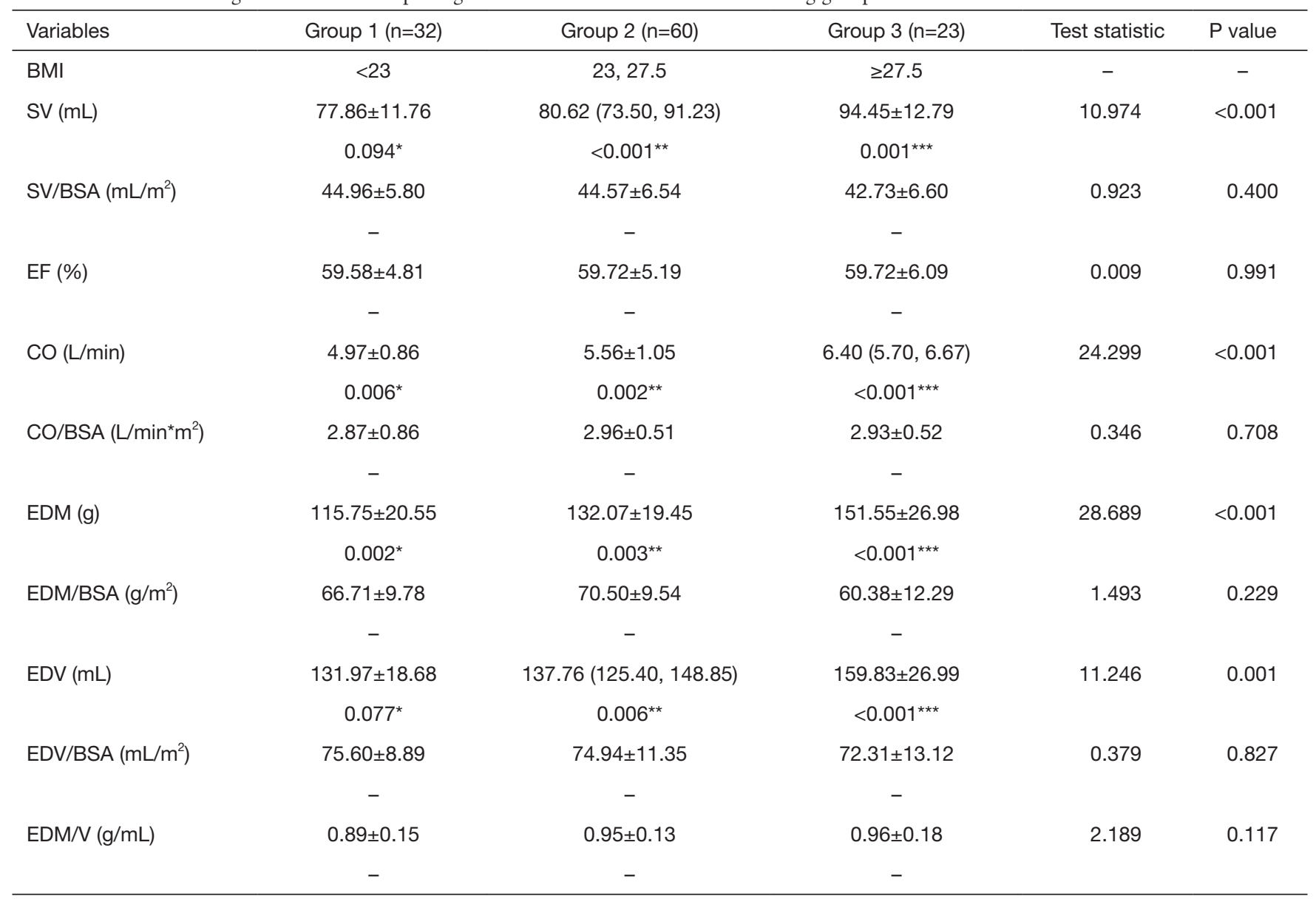

*, $\mathrm{P}$ value for differences between Group 1 and Group 2; ${ }^{*}, \mathrm{P}$ value for differences between Group 2 and Group $3 ;{ }^{* *}, \mathrm{P}$ value for differences between Group 1 and Group 3. BMI, body mass index; BSA, body surface area; CO, cardiac output; EDM, end-diastolic mass; EDV, end-diastolic volume; EF, ejection fraction; SV, stroke volume.

VAT, $r=-0.297$ for WC; CEL: $r=-0.479$ for VAT, $r=-0.358$ for WC; LEL: $r=-0.449$ for VAT, $r=-0.319$ for WC; all $\mathrm{P}<0.05)$. Non-significant or weak associations were found of SR ratio with SAT and HC, respectively.

In addition, SR ratio showed weak correlations with volume-related remodeling indices, especially EDV/ BSA ( $r=0.345,0.265$ and 0.205 for REL, CEL and LEL, respectively, all $\mathrm{P}<0.05)$ and $\mathrm{EDM} / \mathrm{V}(\mathrm{r}=-0.289,-0.252$ and -0.212 for REL, CEL and LEL, respectively, all $\mathrm{P}<0.05$ ). Non-significant associations were found of SR ratio with both mass-related indices and EDV.

\section{Stepwise multivariate linear regression analysis}

Table 4 delineates the factors contributing to diastolic function as assessed by the SR ratio. The variance inflation factors of all models were less than 1.5. The strongest correlates of REL were EAT $(\beta=-0.439, \mathrm{P}<0.001)$ and EDV/BSA $(\beta=0.286, \mathrm{P}<0.001)$. EAT and VAT accounted for most of CEL $(\beta=-0.337,-0.216$, all $\mathrm{P}<0.05)$. The strongest correlates of LEL was VAT $(\beta=-0.355, \mathrm{P}<0.001)$. Notably, $\mathrm{BMI}$ was not a significant predictor of any SR ratio in these models. There was an extreme point in Group 2 (Figure 1). A detailed comparison with another participant having the same BMI is shown in Figure 2. The lower EAT and VAT and higher EDV/BSA might have resulted in the comparatively higher REL, CEL, and LEL.

\section{Discussion}

This study evaluated the associations of fat distribution indices with subclinical diastolic dysfunction in obese 
Table 3 Differences of strain rate parameters among groups

\begin{tabular}{|c|c|c|c|c|c|}
\hline Variables & Group 1 (n=32) & Group $2(n=60)$ & Group $3(n=23)$ & Test statistic & $P$ value \\
\hline \multirow[t]{2}{*}{ REL } & $4.63 \pm 1.24$ & $2.92(2.41,4.28)$ & $3.12 \pm 1.14$ & 20.667 & 0.001 \\
\hline & $<0.001^{*}$ & $0.547^{\star \star}$ & $<0.001^{\star \star \star}$ & & \\
\hline CEL & $2.96 \pm 0.62$ & $2.45 \pm 0.95$ & $2.12 \pm 0.58$ & 7.675 & 0.001 \\
\hline \multirow[t]{2}{*}{ LEL } & $2.20 \pm 0.63$ & $1.83 \pm 0.62$ & $1.63 \pm 0.50$ & 6.640 & 0.002 \\
\hline & $0.007^{\star}$ & $0.164^{\star \star}$ & $0.001^{\star * *}$ & & \\
\hline \multirow[t]{2}{*}{$\mathrm{RSR}_{\mathrm{E}}(/ \mathrm{s})$} & $-128.66 \pm 29.14$ & $-113.63 \pm 32.68$ & $-104.99 \pm 26.77$ & 4.397 & 0.015 \\
\hline & $0.027^{\star}$ & $0.253^{\star \star}$ & $0.006^{\star \star *}$ & & \\
\hline \multirow[t]{2}{*}{$\mathrm{LSR}_{\mathrm{E}}(/ \mathrm{s})$} & $88.36 \pm 18.11$ & $84.10 \pm 19.26$ & $86.96 \pm 18.20$ & 0.589 & 0.557 \\
\hline & - & - & - & & \\
\hline \multirow[t]{2}{*}{$\mathrm{RSR}_{\mathrm{L}}(/ \mathrm{s})$} & $-29.46 \pm 8.17$ & $-36.95 \pm 12.92$ & $-36.25 \pm 10.46$ & 4.842 & 0.010 \\
\hline & $0.003^{*}$ & $0.803^{\star \star}$ & $0.030^{\star \star \star}$ & & \\
\hline \multirow[t]{2}{*}{$\mathrm{CSR}_{\mathrm{L}}(/ \mathrm{s})$} & $45.62(42.44,55.96)$ & $61.16 \pm 19.78$ & $66.97 \pm 18.58$ & 20.144 & $<0.001$ \\
\hline & $<0.001^{*}$ & $0.166^{\star *}$ & $<0.001^{\star \star \star}$ & & \\
\hline \multirow[t]{2}{*}{$\operatorname{LSR}_{\mathrm{L}}(/ \mathrm{s})$} & $41.40 \pm 6.41$ & $48.32 \pm 10.29$ & $56.81 \pm 15.07$ & 14.240 & $<0.001$ \\
\hline & $0.003^{*}$ & $<0.001^{\star \star}$ & $<0.001^{\star \star \star}$ & & \\
\hline
\end{tabular}

*, P value for differences between Group 1 and Group 2; ${ }^{*}, \mathrm{P}$ value for differences between Group 2 and Group 3; ***, $\mathrm{P}$ value for differences between Group 1 and Group 3. BMI, body mass index; CEL, ratio of circumferential early and late diastolic strain rate; CSR peak early diastolic circumferential strain rate; $\mathrm{CSR}_{\mathrm{L}}$, peak late diastolic circumferential strain rate; LEL, ratio of longitudinal early and late diastolic strain rate; $L_{S R}$, peak early diastolic longitudinal strain rate; $L S R_{L}$, peak late diastolic longitudinal strain rate; $R E L$, ratio of radial early and late diastolic strain rate; $\mathrm{RSR}_{\mathrm{E}}$, peak early diastolic radial strain rate; $\mathrm{RSR}_{\mathrm{L}}$, peak late diastolic radial strain rate.

Chinese men assessed by DRA-based myocardial SR analysis. Morphological and functional parameters indicated compensatory elevated hemodynamic state and $\mathrm{LV}$ remodeling in obesity. Moreover, diastolic function assessed by SR ratios exhibited a significant decrease in obese men. Instead of BMI, we found that EAT and VAT were potentially better predictors of subclinical diastolic dysfunction assessed by SR ratios in obesity.

Decreased diastolic function with increasing BMI has been described using both speckle-tracking and tissue Doppler imaging (TDI) $(4,6,31,32)$. In addition, BMI and/ or duration of obesity are predictors of impaired cardiac function (33,34). Different from previous studies that focused on the global cardiac function of obesity, this study was oriented towards patterns of $\mathrm{LV}$ deformation during both early and late diastole. We found that obesity had an unequal effect on fibers in diverse directions in different diastolic periods. Only $\mathrm{RSR}_{\mathrm{E}}$ showed a significant decrease, while late SRs significantly increased in subjects with higher BMI. These findings indicate that diastolic dysfunction caused by obesity might start with increasing stiffness of the myocardium, which is considered to contribute to heart failure progression with preserved EF (35). Comparable results were also reported by Barbosa et al. $(32,36,37)$. However, Peterson et al. reported a significant decrease in early diastolic myocardial velocity instead of an increase of late velocity in obesity using TDI (4). Other studies demonstrated changes of both $\mathrm{E}$ and $\mathrm{A}$ waves, indicating impairment of both active relaxation and passive stiffness of the myocardium in obesity $(6,38)$. 
These studies all examined non-Chinese population using a cut-off value of BMI recommended by the World Health Organization (WHO), which might be responsible for these discrepancies. For another, the SR was not completely the same principle as the E or A wave in echocardiology (13).

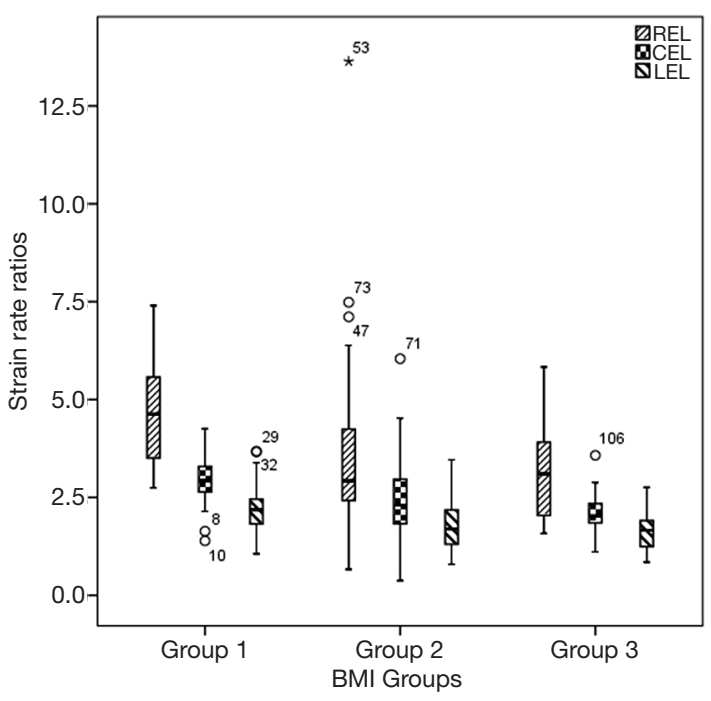

Figure 1 Boxplots for ratios of strain rate among the 3 groups. Groups 1, 2, 3 consisted of lean, overweight, and obese participants (BMI: $<23,23$ to $27.5, \geq 27.5 \mathrm{~kg} / \mathrm{m}^{2}$, respectively). CEL, ratio of circumferential early and late diastolic strain rate; LEL, ratio of longitudinal early and late diastolic strain rate; REL, ratio of radial early and late diastolic strain rate. *, outliers in Group 2.
Further investigations with a larger Chinese population using SR analysis are required to confirm our present results.

Notably, previous studies have reported a decrease of E/A ratio in obesity $(4,6,32,38)$. In the current study, we also found that all SR ratios, to some extent, similar to E/ A, exhibited a significant decrease in both overweight and obese groups compared with lean individuals. In addition, the load increase in obesity might contribute more than mass to diastolic function assessed by SR ratios. EDV/ $\mathrm{BSA}, \mathrm{SV} / \mathrm{BSA}$, and the remodeling index $(\mathrm{EDM} / \mathrm{V})$ were correlated with all SR ratios. Meanwhile, EDV/BSA was the only morphological determinant of REL and CEL. No SR ratios showed a significant correlation with myocardial mass. This might indicate that the motion of myocardial fibers might be more vulnerable to increasing load/volume in obesity.

$\mathrm{BMI}$ is a global measurement rather than reflecting fat distribution in obesity. Therefore, it might be limited in evaluating the effect of obesity on certain organs. In this study, we have discussed the correlation between fat distributions and diastolic function and found VAT and EAT contributed more to change of the latter than BMI. SR ratios were correlated with most fat distribution indices. In addition, EAT was found to be the common predictor of REL and CEL, while VAT also contributed to CEL and LEL. Instead of BMI, which has been widely considered in most literatures $(32,33)$, our results suggested EAT and VAT were a better predictor of diastolic cardiac function

Table 4 Multiple stepwise regression analysis of the diastolic function

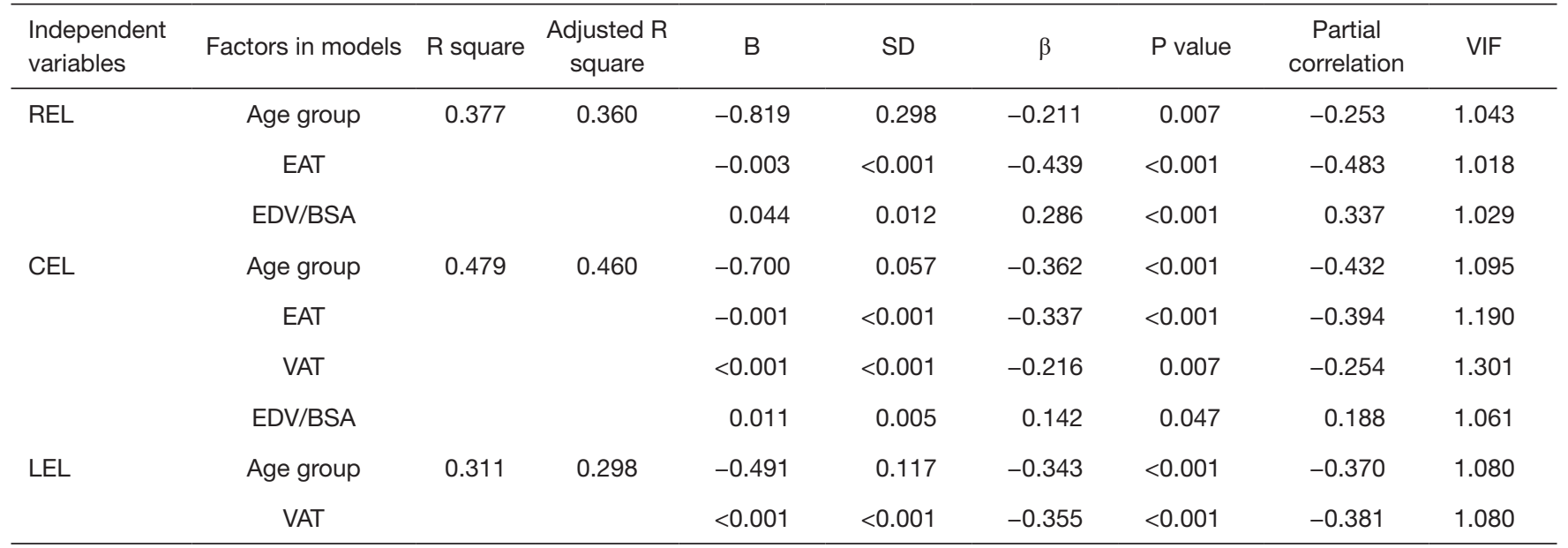

BSA, body surface area; CEL, ratio of circumferential early and late diastolic strain rate; EAT, epicardial fat; EDV, end-diastolic volume; LEL, ratio of longitudinal early and late diastolic strain rate; REL, ratio of radial early and late diastolic strain rate; VAT, visceral adipose tissue. 

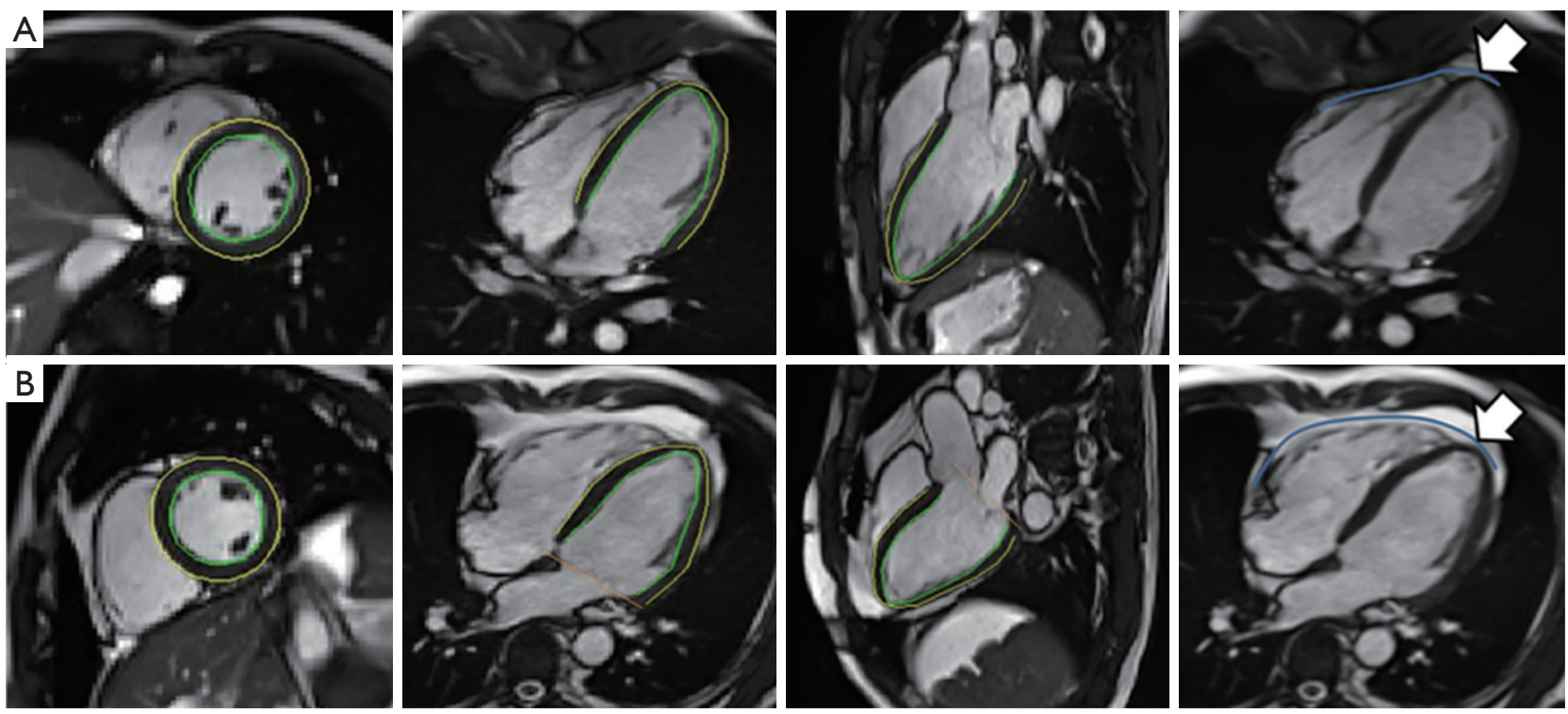

Figure 2 Two participants with the same BMI but different fat distribution and SR ratios. Endo-myocardial (green line), epi-myocardial (yellow line), and part of the pericardium contour (arrow and blue line) were shown on mid-ventricular short-axis, 4-chamber, and 3-chamber images. (A) End-diastolic images of a 24-year-old male with BMI of $23.39 \mathrm{~kg} / \mathrm{m}^{2}$. Part parameters were as follows: VAT =1,005.28 $\mathrm{cm}^{3}$; SAT $=3,912.80 \mathrm{~cm}^{3}$; EAT $=111.93 \mathrm{~mm}^{2}$; PAT $=184.53 \mathrm{~mm}^{2}$; EDV/BSA =80.28 mL/m² REL =13.64; CEL =4.53; LEL =3.46. (B) End-diastolic images of a 35 -year-old male with a BMI of $23.39 \mathrm{~kg} / \mathrm{m}^{2}$. Part parameters were as follows: VAT $=3,666.76 \mathrm{~cm}^{3} ; \mathrm{SAT}^{2}=3,982.33 \mathrm{~cm}^{3} ; \mathrm{EAT}$ $=716.86 \mathrm{~mm}^{2}$; PAT =1,395.42 $\mathrm{mm}^{2}$; EDV/BSA =69.70 mL/m²; REL =2.06; CEL =2.08; LEL =1.70. BSA, body surface area; CEL, ratio of circumferential early and late diastolic strain rate; EAT, epicardial adipose tissue; EDV, end-diastolic volume; LEL, ratio of longitudinal early and late diastolic strain rate; PAT, pericardial adipose tissue; REL, ratio of radial early and late diastolic strain rate; SAT, subcutaneous adipose tissue; SR, strain rate; VAT, visceral adipose tissue.

in obesity, and thus they might be of great significance in both making individual medical treatment and longitudinal follow-up after therapy in severe obesity.

Furthermore, no mass-associated indices participated in these models. This is in disagreement with the notion that myocardial stiffness and thus decreased diastolic function is caused by hypertrophy (39). The current findings indicate that myocardial diastolic dysfunction, especially stiffness, might be influenced not only by hypertrophy but also by metabolic dysfunction or inflammatory changes of the myocardium as a result of increased VAT and EAT. Previous studies have demonstrated that VAT and EAT function not only as lipid-storing tissues but also constitute metabolically active and inflammatory tissues secreting cytokines and chemokines that affect cardiac morphology and function (40-44). Putatively, free fatty acids (FFA) released from hypertrophied adipocytes in EAT could diffuse directly into the myocardium, together with myocardial uptake of plasma FFA, exacerbating myocardial steatosis, lipotoxicity, and even fibrosis, and hence a spectrum of structurally and functionally cardiac changes (39). Since few reports have assessed SR ratios, future studies are needed to confirm our hypothesis.

Moreover, as a result of excessive fat in obesity, larger $\mathrm{SV}, \mathrm{CO}, \mathrm{EDV}$, and EDM were found with higher BMI, indicating both a functionally absolute increase in total blood volume and $\mathrm{CO}$ and morphological LV dilation and hypertrophy. Similarly, SV/BSA, CO/BSA, EDV/ BSA, and EDM/BSA among the groups implied both functional and morphological changes were all within complete compensatory range. Previous studies have reported a similar tendency of change in obesity using echocardiography $(4,6,32,33)$.

This study has limitations. Firstly, since obesity is the main risk factor for obstructive sleep apnea and adipokines, and FFA easily diffuses from EAT into the right ventricle (RV) $(15,45)$, it is also important to explore RV dysfunction in obesity. Unfortunately, SR analysis of RV was not performed. Secondly, the female population was not included, although obese women are at higher risk for 
developing heart failure (46). In addition, fat distribution patterns in women are different (7) and should be discussed in further studies. Finally, our results need to be validated by echocardiography or other similar image processing techniques, which could not be included this time.

\section{Conclusions}

Decreased LV diastolic function assessed by DRA-based SR analysis in obesity is associated with fat distribution. Furthermore, EAT and VAT might be better predictors than BMI of decreased diastolic function in Chinese men with obesity.

\section{Acknowledgments}

Funding: None.

\section{Footnote}

Conflicts of Interest: The authors have no conflicts of interest to declare.

Ethical Statement: This prospective study was approved by the institutional review board, and written informed consent was obtained from each participant.

Open Access Statement: This is an Open Access article distributed in accordance with the Creative Commons Attribution-NonCommercial-NoDerivs 4.0 International License (CC BY-NC-ND 4.0), which permits the noncommercial replication and distribution of the article with the strict proviso that no changes or edits are made and the original work is properly cited (including links to both the formal publication through the relevant DOI and the license). See: https://creativecommons.org/licenses/by-nc-nd/4.0/.

\section{References}

1. Tian Y, Jiang C, Wang M, Cai R, Zhang Y, He Z, Wang H, Wu D, Wang F, Liu X, He Z, An P, Wang M, Tang Q, Yang Y, Zhao J, Lv S, Zhou W, Yu B, Lan J, Yang X, Zhang L, Tian H, Gu Z, Song Y, Huang T, McNaughton LR. BMI, leisure-time physical activity, and physical fitness in adults in China: results from a series of national surveys, 2000-14. Lancet Diabetes Endocrinol 2016;4:487-97.

2. Rao G, Powell-Wiley TM, Ancheta I, Hairston K, Kirley K, Lear SA, North KE, Palaniappan L, Rosal
MC; American Heart Association Obesity Committee of the Council on Lifestyle and Cardiometabolic Health. Identification of Obesity and Cardiovascular Risk in Ethnically and Racially Diverse Populations: A Scientific Statement From the American Heart Association. Circulation 2015;132:457-72.

3. Alpert MA. Obesity cardiomyopathy: pathophysiology and evolution of the clinical syndrome. Am J Med Sci 2001;321:225-36.

4. Peterson LR, Waggoner AD, Schechtman KB, Meyer T, Gropler RJ, Barzilai B, Dávila-Román VG. Alterations in left ventricular structure and function in young healthy obese women: assessment by echocardiography and tissue Doppler imaging. J Am Coll Cardiol 2004;43:1399-404.

5. Palmieri V, de Simone G, Arnett DK, Bella JN, Kitzman DW, Oberman A, Hopkins PN, Province MA, Devereux RB. Relation of various degrees of body mass index in patients with systemic hypertension to left ventricular mass, cardiac output, and peripheral resistance (The Hypertension Genetic Epidemiology Network Study). Am J Cardiol 2001;88:1163-8.

6. Pascual M, Pascual DA, Soria F, Vicente T, Hernández AM, Tébar FJ, Valdés M. Effects of isolated obesity on systolic and diastolic left ventricular function. Heart 2003;89:1152-6.

7. Cornier MA, Despres JP, Davis N, Grossniklaus DA, Klein S, Lamarche B, Lopez-Jimenez F, Rao G, St-Onge MP, Towfighi A, Poirier P; American Heart Association Obesity Committee of the Council on Nutrition; Physical Activity and Metabolism; Council on Arteriosclerosis; Thrombosis and Vascular Biology; Council on Cardiovascular Disease in the Young; Council on Cardiovascular Radiology and Intervention; Council on Cardiovascular Nursing, Council on Epidemiology and Prevention; Council on the Kidney in Cardiovascular Disease, and Stroke Council. Assessing adiposity: a scientific statement from the American Heart Association. Circulation 2011;124:1996-2019.

8. Lebovitz HE. The relationship of obesity to the metabolic syndrome. Int J Clin Pract Suppl 2003;(134):18-27.

9. Wildman RP, Gu D, Reynolds K, Duan X, He J. Appropriate body mass index and waist circumference cutoffs for categorization of overweight and central adiposity among Chinese adults. Am J Clin Nutr 2004;80:1129-36.

10. Gill T. Epidemiology and health impact of obesity: an Asia Pacific perspective. Asia Pac J Clin Nutr 2006;15 Suppl:3-14.

11. World Health O. The Asia-Pacific perspective: redefining 
obesity and its treatment: Sydney: Health Communications Australia, 2000.

12. Wang M, Luo Y, Cai H, Xu L, Huang M, Li C, Dong Z, Li ZP, Feng ST. Prediction of type 2 diabetes mellitus using noninvasive MRI quantitation of visceral abdominal adiposity tissue volume. Quant Imaging Med Surg 2019;9:1076-86.

13. Duncan AE, Alfirevic A, Sessler DI, Popovic ZB, Thomas JD. Perioperative assessment of myocardial deformation. Anesth Analg 2014;118:525-44.

14. Kishi S, Armstrong AC, Gidding SS, Colangelo LA, Venkatesh BA, Jacobs DR Jr, Carr JJ, Terry JG, Liu K, Goff DC Jr, Lima JA. Association of obesity in early adulthood and middle age with incipient left ventricular dysfunction and structural remodeling: the CARDIA study (Coronary Artery Risk Development in Young Adults). JACC Heart Fail 2014;2:500-8.

15. Wong CY, O'Moore-Sullivan T, Leano R, Hukins C, Jenkins C, Marwick TH. Association of Subclinical Right Ventricular Dysfunction With Obesity. J Am Coll Cardiol 2006;47:611-6.

16. Schuster A, Paul M, Bettencourt N, Morton G, Chiribiri A, Ishida M, Hussain S, Jogiya R, Kutty S, Bigalke B, Perera D, Nagel E. Cardiovascular magnetic resonance myocardial feature tracking for quantitative viability assessment in ischemic cardiomyopathy. Int J Cardiol 2013;166:413-20.

17. Smith BM, Dorfman AL, Yu S, Russell MW, Agarwal PP, Ghadimi Mahani M, Lu JC. Relation of strain by feature tracking and clinical outcome in children, adolescents, and young adults with hypertrophic cardiomyopathy. Am J Cardiol 2014;114:1275-80.

18. Kalaitzidis P, Orwat S, Kempny A, Robert R, Peters B, Sarikouch S, Beerbaum P, Baumgartner H, Diller GP; Competence Network for Congenital Heart Defects, DZHK (German Center for Cardiovascular Research). Biventricular dyssynchrony on cardiac magnetic resonance imaging and its correlation with myocardial deformation, ventricular function and objective exercise capacity in patients with repaired tetralogy of Fallot. Int J Cardiol 2018;264:53-7.

19. Wang J, Li W, Sun J, Liu H, Kang Y, Yang D, Yu L, Greiser A, Zhou X, Han Y, Chen Y. Improved segmental myocardial strain reproducibility using deformable registration algorithms compared with feature tracking cardiac MRI and speckle tracking echocardiography. J Magn Reson Imaging 2018;48:404-14.

20. Wan K, Sun J, Yang D, Liu H, Wang J, Cheng W, Zhang
Q, Zeng Z, Zhang T, Greiser A, Jolly MP, Han Y, Chen Y. Left Ventricular Myocardial Deformation on Cine MR Images: Relationship to Severity of Disease and Prognosis in Light-Chain Amyloidosis. Radiology 2018;288:73-80.

21. Lin K, Collins JD, Chowdhary V, Markl M, Carr JC. Heart deformation analysis for automated quantification of cardiac function and regional myocardial motion patterns: A proof of concept study in patients with cardiomyopathy and healthy subjects. Eur J Radiol 2016;85:1811-7.

22. Lee CS, Murphy DJ, McMahon C, Nolan B, Cullen G, Mulcahy H, Sheahan K, Barnes E, Fennelly D, Ryan EJ, Doherty GA. Visceral Adiposity is a Risk Factor for Poor Prognosis in Colorectal Cancer Patients Receiving Adjuvant Chemotherapy. J Gastrointest Cancer 2015;46:243-50.

23. Granér M, Siren R, Nyman K, Lundbom J, Hakkarainen A, Pentikainen MO, Lauerma K, Lundbom N, Adiels M, Nieminen MS, Taskinen MR. Cardiac steatosis associates with visceral obesity in nondiabetic obese men. J Clin Endocrinol Metab 2013;98:1189-97.

24. Sicari R, Sironi AM, Petz R, Frassi F, Chubuchny V, De Marchi D, Positano V, Lombardi M, Picano E, Gastaldelli A. Pericardial rather than epicardial fat is a cardiometabolic risk marker: an MRI vs echo study. J Am Soc Echocardiogr 2011;24:1156-62.

25. Al-Talabany S, Mordi I, Graeme Houston J, Colhoun HM, Weir-McCall JR, Matthew SZ, Looker HC, Levin D, Belch JJF, Dove F, Khan F, Lang CC. Epicardial adipose tissue is related to arterial stiffness and inflammation in patients with cardiovascular disease and type 2 diabetes. BMC Cardiovasc Disord 2018;18:31.

26. Fedorov A, Beichel R, Kalpathy-Cramer J, Finet J, FillionRobin JC, Pujol S, Bauer C, Jennings D, Fennessy F, Sonka M, Buatti J, Aylward S, Miller JV, Pieper S, Kikinis R. 3D Slicer as an image computing platform for the Quantitative Imaging Network. Magn Reson Imaging 2012;30:1323-41.

27. Urheim S, Edvardsen T, Torp H, Angelsen B, Smiseth OA. Myocardial strain by Doppler echocardiography. Validation of a new method to quantify regional myocardial function. Circulation 2000;102:1158-64.

28. Meng L, Lin K, Collins J, Markl M, Carr JC. Automated Description of Regional Left Ventricular Motion in Patients With Cardiac Amyloidosis: A Quantitative Study Using Heart Deformation Analysis. AJR Am J Roentgenol 2017;209:W57-W63.

29. Lin K, Collins JD, Lloyd-Jones DM, Jolly MP, Li D, Markl M, Carr JC. Automated Assessment of Left 
Ventricular Function and Mass Using Heart Deformation Analysis: Initial Experience in 160 Older Adults. Acad Radiol 2016;23:321-5.

30. Zhu L, Pan Z, Ma Q, Yang W, Shi H, Fu C, Yan X, Du L, Yan F, Zhang H. Diffusion Kurtosis Imaging Study of Rectal Adenocarcinoma Associated with Histopathologic Prognostic Factors: Preliminary Findings. Radiology 2017;284:66-76.

31. Lorch SM, Sharkey A. Myocardial velocity, strain, and strain rate abnormalities in healthy obese children. J Cardiometab Syndr 2007;2:30-4.

32. Barbosa MM, Beleigoli AM, de Fatima Diniz M, Freire CV, Ribeiro AL, Nunes MC. Strain imaging in morbid obesity: insights into subclinical ventricular dysfunction. Clin Cardiol 2011;34:288-93.

33. Wong CY, O'Moore-Sullivan T, Leano R, Byrne N, Beller $\mathrm{E}$, Marwick TH. Alterations of left ventricular myocardial characteristics associated with obesity. Circulation 2004;110:3081-7.

34. Alpert MA, Lambert CR, Terry BE, Cohen MV, Mukerji V, Massey CV, Hashimi MW, Panayiotou H. Interrelationship of left ventricular mass, systolic function, and diastolic filling in normotensive morbidly obese patients. Int J Obes Relat Metab Disord 1995;19:550-7.

35. Ohtani T, Mohammed SF, Yamamoto K, Dunlay SM, Weston SA, Sakata Y, Rodeheffer RJ, Roger VL, Redfield MM. Diastolic stiffness as assessed by diastolic wall strain is associated with adverse remodelling and poor outcomes in heart failure with preserved ejection fraction. Eur Heart J 2012;33:1742-9.

36. Chakko S, Mayor M, Allison MD, Kessler KM, Materson BJ, Myerburg RJ. Abnormal left ventricular diastolic filling in eccentric left ventricular hypertrophy of obesity. Am J Cardiol 1991;68:95-8.

37. Wang YC, Liang CS, Gopal DM, Ayalon N, Donohue C, Santhanakrishnan R, Sandhu H, Perez AJ, Downing

Cite this article as: Zhu L, Gu S, Wang Q, Zhou X, Wang S, Fu C, Yang W, Wetzl J, Yan F. Left ventricular myocardial deformation: a study on diastolic function in the Chinese male population and its relationship with fat distribution. Quant Imaging Med Surg 2020;10(3):634-645. doi: 10.21037/ qims.2020.01.16
J, Gokce N, Colucci WS, Ho JE. Preclinical Systolic and Diastolic Dysfunctions in Metabolically Healthy and Unhealthy Obese Individuals. Circ Heart Fail 2015;8:897-904.

38. Iacobellis G, Ribaudo MC, Leto G, Zappaterreno A, Vecci E, Di Mario U, Leonetti F. Influence of excess fat on cardiac morphology and function: study in uncomplicated obesity. Obes Res 2002;10:767-73.

39. von Bibra H, St John Sutton M. Diastolic dysfunction in diabetes and the metabolic syndrome: promising potential for diagnosis and prognosis. Diabetologia 2010;53:1033-45.

40. Mazurek T, Zhang L, Zalewski A, Mannion JD, Diehl JT, Arafat H, Sarov-Blat L, O'Brien S, Keiper EA, Johnson AG, Martin J, Goldstein BJ, Shi Y. Human epicardial adipose tissue is a source of inflammatory mediators. Circulation 2003;108:2460-6.

41. Sacks HS, Fain JN. Human epicardial adipose tissue: a review. Am Heart J 2007;153:907-17.

42. Iacobellis G, Pond CM, Sharma AM. Different "weight" of cardiac and general adiposity in predicting left ventricle morphology. Obesity (Silver Spring) 2006;14:1679-84.

43. Fontana L, Eagon JC, Trujillo ME, Scherer PE, Klein S. Visceral fat adipokine secretion is associated with systemic inflammation in obese humans. Diabetes 2007;56:1010-3.

44. Malavazos AE, Ermetici F, Coman C, Corsi MM, Morricone L, Ambrosi B. Influence of epicardial adipose tissue and adipocytokine levels on cardiac abnormalities in visceral obesity. Int J Cardiol 2007;121:132-4.

45. Iacobellis G, Corradi D, Sharma AM. Epicardial adipose tissue: anatomic, biomolecular and clinical relationships with the heart. Nat Clin Pract Cardiovasc Med 2005;2:536-43.

46. Kenchaiah S, Evans JC, Levy D, Wilson PW, Benjamin EJ, Larson MG, Kannel WB, Vasan RS. Obesity and the risk of heart failure. N Engl J Med 2002;347:305-13. 


\section{Supplementary}

Table S1 Correlation of strain rate ratios with fat distributions and morphological factors

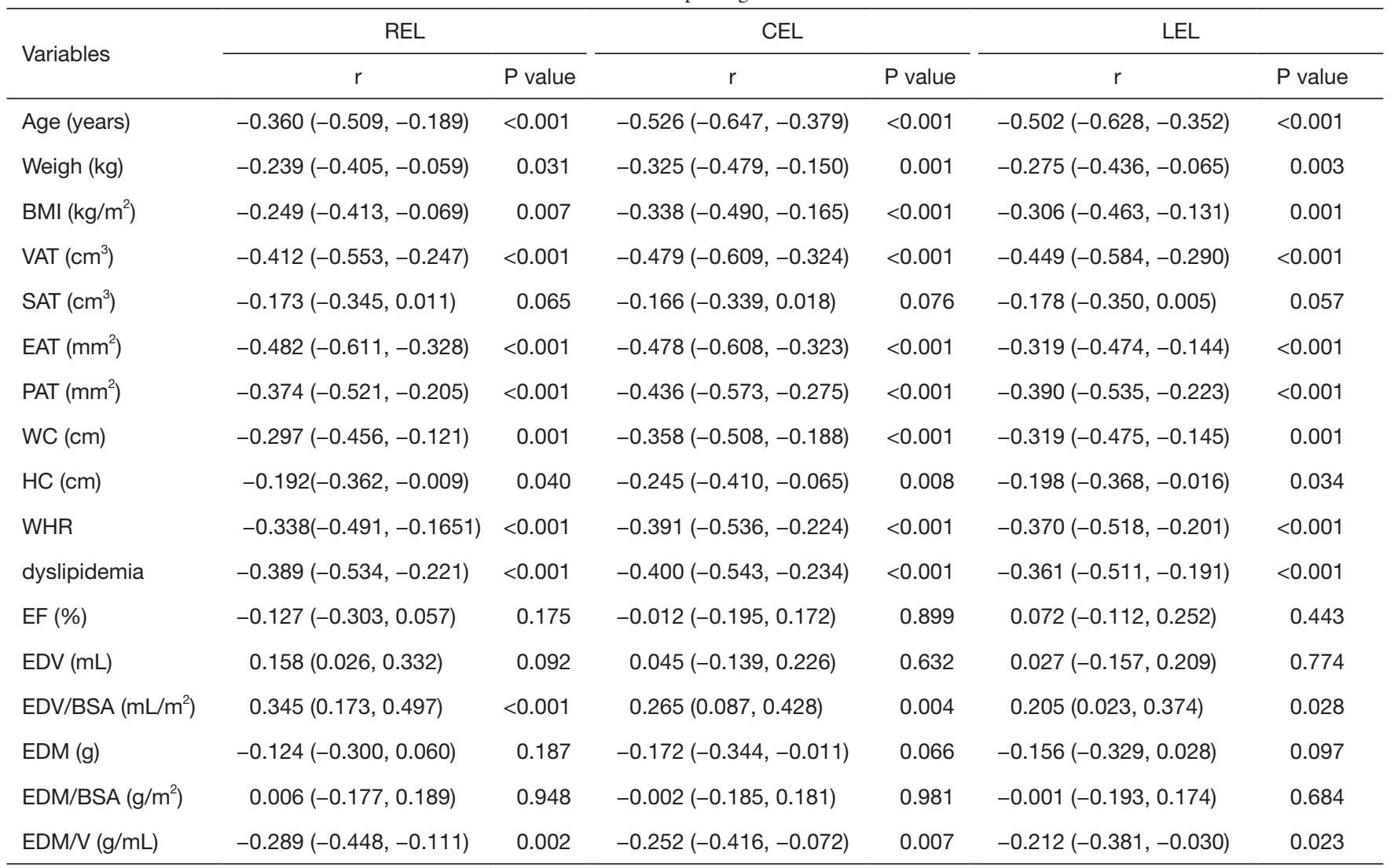

BMI, body mass index; BSA, body surface area; CEL, ratio of circumferential early and late diastolic strain rate; EAT, epicardial adipose tissue; EDM, end-diastolic mass; EDV, end-diastolic volume; EF, ejection fraction; HC, hip circumference; LEL, ratio of longitudinal early and late diastolic strain rate; PAT, pericardial adipose tissue; REL, ratio of radial early and late diastolic strain rate; SAT, subcutaneous adipose tissue; VAT, visceral adipose tissue; WC, waist circumference; WHR, waist-to-hip ratio. 